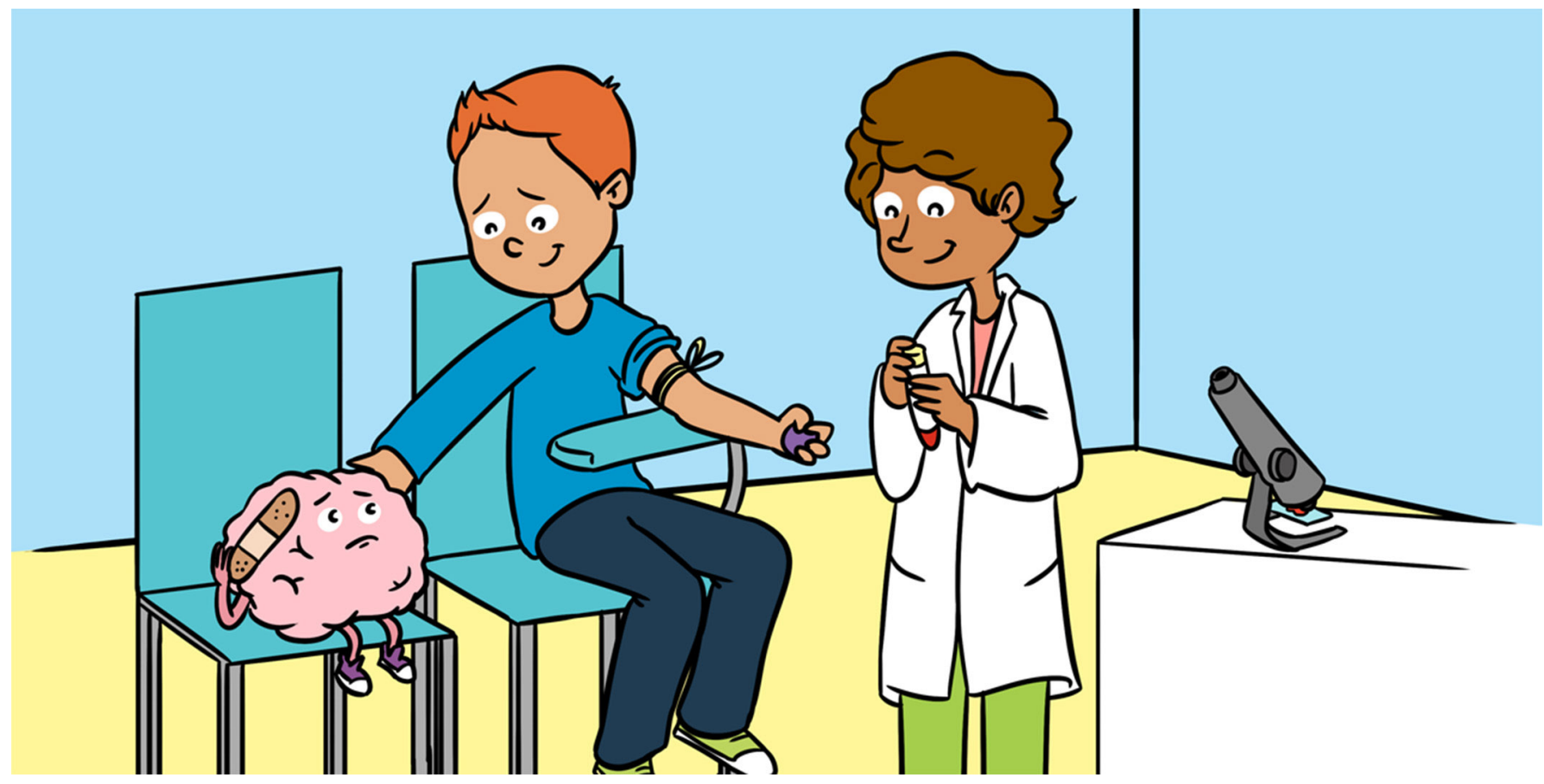

\title{
STUDYING BRAIN INJURY THROUGH THE BLOOD: THE PROMISE OF BIOMARKERS
}

Stephany Kim ${ }^{1,2}$, Preston Klein ${ }^{1,2}$, Mindy Nguyen $^{1,2}$ and Nicole Osier ${ }^{1,2 *}$

${ }^{1}$ Department of Neurology, Dell Medical School, University of Texas at Austin, Austin, TX, United States

2 Holistic Adult Health, School of Nursing, University of Texas at Austin, Austin, TX, United States

YOUNG REVIEWER:

(6) BRITT

Scientists and doctors are trying to identify and develop new and better ways to diagnose brain injury, because brain injuries are hard to detect. Even when a brain is known to be injured, it is hard to treat. This is unfortunate, because traumatic brain injury (TBI) is the most common brain disorder in children. One of the ways to detect TBI is by looking at biomarkers in the blood. Biomarkers, ranging from protein to DNA, help scientists determine whether a part of the body is damaged. Different injuries produce different biomarkers, giving us information on the severity of the injury; and other biomarkers provide clues regarding injury location. Scientists are hoping to use these biomarkers in the blood to see how likely children with TBI are to have a good or bad outcome, and, more importantly, how doctors can better treat children for these injuries. 
TRAUMATIC BRAIN INJURY

Physical trauma to the brain that can affect thinking and cognitive abilities.
Figure 1

Two of the most commonly used imaging techniques for patients with TBI. (CT image: https://www. flickr.com/photos/ ciscel/124548696/; MRI image: https:// pixabay.com/en/ mri-magnetic-x-rayskull-head-782459/)

\section{WHAT IS TRAUMATIC BRAIN INJURY (TBI)?}

Traumatic brain injury (TBI) is one of the most common brain disorders in children. $\mathrm{TBI}$ often occurs due to a strong blow to the head from getting hit by an object, running into an object, or falling on one's head. $\mathrm{TBI}$ can be very dangerous because it can severely damage the brain, which is critical for controlling the body and the personality, as well as speech, movement, and much more. Depending on what part of the brain is hurt, there can be serious consequences. Because of this, it is important to be able to diagnose a TBI as soon as it happens.

\section{HOW DO WE CURRENTLY STUDY THE BRAIN AND WHAT ARE THE LIMITATIONS OF THESE METHODS?}

When the brain is damaged, the consequences of the injury can be very serious. However, studying the brain is difficult, because the brain is enclosed in the skull. Therefore, it is hard to tell whether or not there is injury and how severe it is. Currently, the most common way to look inside the brain is through a process called imaging, with several types of images giving us different insights into the brain. Think of the different types of options on a camera. A panorama gives you a wide picture of what is happening. Other times, you take a video, so you can document the event in real time. Similarly, different imaging methods give us different information about brain injuries. The two most common types of imaging used on patients with TBI are shown in Figure 1.

Although imaging is currently the most used technique for diagnosing $\mathrm{TBI}$, there are quite a few problems with these methods. First, the images often fail to detect problems in the brain after an injury. Moreover, medications, blood sugar levels, or even changes in the

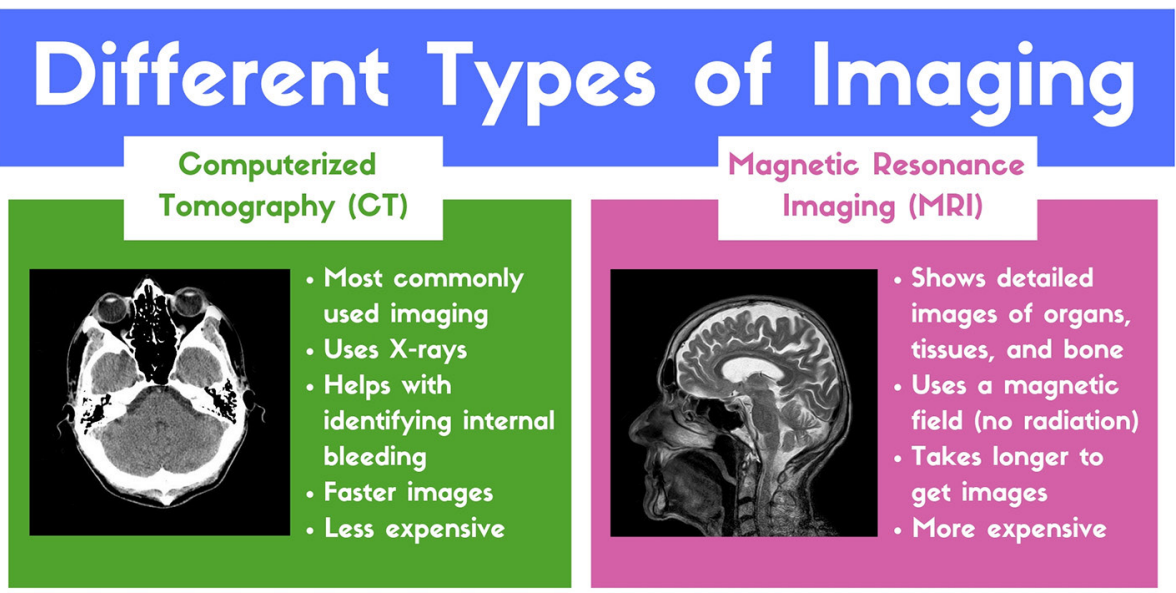

Figure 1 
patient's emotional state can affect brain activity. This in turn can lead to inaccurate readings that look like a brain injury, leading to false conclusions. This is important, considering the second drawback: the fact that imaging is very expensive! The average cost to run scans can be a couple thousand dollars! Because of this, it is important for hospitals to minimize the number of scans that show no injuries, often referred to as negative scans. Also, because many of these methods essentially take pictures of the brain at a given moment in time, it is difficult to see how an injury develops, improves, or worsens over time without doing additional scans and spending more money [1]. And of course, some kinds of imaging, like CT scans and PET scans, use radiation or radioactive substances to look at the brain, and radiation is associated with a small risk of developing cancer.

\section{WHY IS USING THE BLOOD A WORTHWHILE WAY TO STUDY THE BRAIN?}

So, why are scientists looking at blood as a way to study brain injury? The first reason is that blood is easy to obtain from patients, using an IV line or through a simple blood draw from a vein in the hand. Since patients typically give blood to test for levels of other molecules in the body, such as glucose or iron, a blood test is an easy way to look for other markers in the blood that may tell us more about the brain injury. Second, drawing blood is a low-risk procedure, with the main risks being bruising, pain, and infection. Last, drawing blood is an inexpensive method for research and diagnostic tests! Compared with the thousands of dollars spent on expensive imaging, blood tests are a more affordable means of diagnostic testing, both for the hospitals and the patients.

\section{BIOMARKER}

A biological molecule within the body that can be measured. Data from the presence and levels of biomarkers allows scientists to detect abnormalities and diseases in a patient.

\section{EXOSOME}

Vesicles that are released from cell and can travel through various bodily fluids. An exosome can contain molecules that indicate which cell it came from and what was happening in that cell.

\section{WHAT CAN WE MEASURE IN THE BLOOD?}

A biomarker is a molecule that can be analyzed to reveal information regarding the biological processes that are happening in the body [2]. For instance, your blood level of glucose is a biomarker that tells doctors if you are at risk for diabetes. Since diagnosing TBI quickly gives patients a better chance of recovery, discovering biomarkers that can be used to rapidly diagnose TBI would be extremely helpful. The three potential types of biomarkers being researched for diagnosing TBI are proteins, DNA/RNA, and exosomes (Figure 2).

Protein biomarkers are one of the most commonly studied [3]. Following $\mathrm{TBI}$, the levels of certain proteins can increase or decrease, as a result of changes happening within brain cells that have been injured. Scientists can measure the levels of those specific proteins in a person's blood, 
Figure 2

Biomarkers that are often used to detect TBI. Deoxyribonucleic acid (DNA) is the genetic material that tells each of our cells how to make all the proteins it needs. When cells are in the process of making proteins, DNA is first used to make ribonucleic acid (RNA). Both DNA and RNA can be used as biomarkers, as can the proteins they code for. An exosome is essentially a bubble (shown in blue and green) that is stored inside a cell with other exosomes, in a larger structure called a multivesicular body (shown in pink); each exosome contains various proteins, RNAs, and other molecules (as depicted in orange, red, and purple) that can be released outside the cell, often as a form of cell-to-cell communication

\section{HALF-LIFE}

The amount of time required for a substance to decrease to half of its initial level.

\section{Types of Biomarkers}
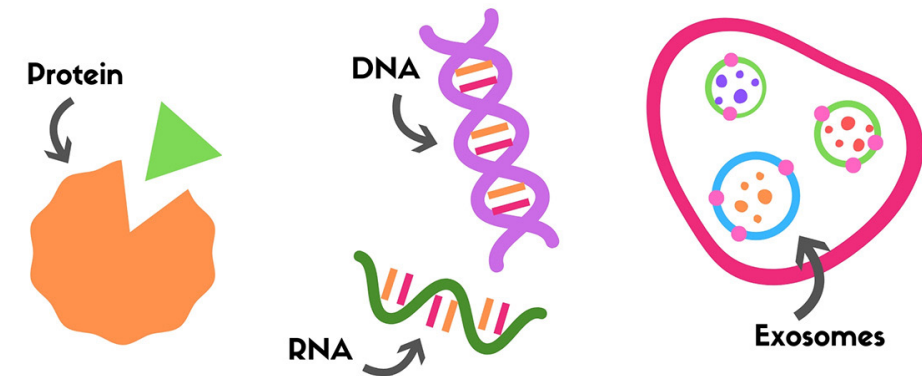

Figure 2

saliva, urine, or other body fluids. Abnormal levels of these proteins can tell us if the patient has a TBI and how likely the patient is to recover. Despite progress, researchers are still searching for the ideal protein biomarker for TBI. Since many protein biomarkers are produced by other cells in addition to brain cells, it is difficult to use those protein biomarkers as definite indicators of brain injury. The different half-life of proteins also makes it difficult to reliably measure the levels of a specific protein. Half-life refers to how long it takes for the level of a protein to decrease by $50 \%$. Some proteins break down quickly in blood, making them difficult to use for biomarker studies.

DNA and RNA are other types of biomarkers being studied. DNA is the molecule that makes up our genetic blueprint, and it is used to make RNA, which is then used to make proteins. The fact that DNA, RNA, and proteins are all related means that all three are potential biomarkers that can tell use slightly different things. As an example, damage to the brain can increase the production of certain proteins, including a protein called calcineurin. Interestingly, some people have slightly different versions of the calcineurin gene that are associated with worse outcomes following TBI [4]. If we can figure out which gene versions are associated with recovery from TBI, we may be able to discover new methods for diagnosis and treatment.

While DNA and proteins are promising potential biomarkers, we cannot really be sure whether they come from the brain or not, since all our cells contain DNA. This uncertainty has led scientists to use something called exosomes as biomarkers. Exosomes are a type of structure called extracellular vesicles (EVs), which are a hot topic in research [5]. Exosomes are stored inside cells in groups called multivesicular bodies, which are like bubbles that fuse with the plasma membrane, releasing the contents (the exosomes) outside of the cell (Figure 3). Think of the plasma membrane as the wall of a balloon. Since each cell has its own unique protein markers, when the multivesicular bodies fuse with the 
Figure 3

Exosomes are stored in a multivesicular body and released outside of the cell into the blood. Exosomes can show us what is happening in a particular cell type, because when they are released, they pick up pieces of the membrane from that cell (shown as pink dots on the outside of the blue and green exosomes in the black box, which have been released from the cell).

\section{CYTOKINE}

A general name for proteins of the immune system that participate in cell communication and affect how other cells behave.

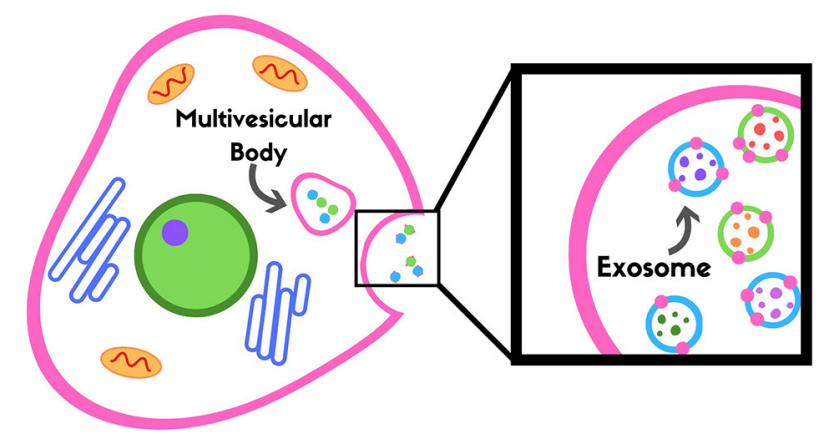

Figure 3

plasma membrane, the exosomes pick up these markers from the cell membrane. As a result, these markers tell us which type of cell the exosome came from and what was happening in that cell. In TBI, the markers present in exosomes might help us to understand what is happening in brain cells following brain injury.

\section{EXAMPLES OF BIOMARKERS USED TO DETECT TBI}

Researchers continue to study many biomarkers to see which ones might be the best for diagnosing TBI. Here are just a few of the potential TBI biomarkers and what they might tell us about brain injury.

GFAP is a protein biomarker that is found only in the cells of the brain and spinal cord. It is a structural protein, meaning it helps the cells maintain their shape. After brain injury, GFAP is released from damaged cells and it gets into the blood, where it can be measured in blood samples. GFAP increases in blood shortly after TBI and gradually decreases over time. GFAP may be helpful in determining how well patients will recover from TBI over time [6].

Another protein biomarker that shows potential is a group of proteins called cytokines. Cytokines are released by the immune system after brain injury. Two cytokines that have shown promise in TBI research are called IL-10 and IL-6. One study found that patients who did not recover well from TBI had IL-10 levels about three times higher than patients who recovered well [7]. IL- 6 has been shown to be beneficial immediately following TBI, but if the level of IL- 6 stays elevated for too long, it can actually harm patient recovery [8]. Further research with IL-6 may allow us to track how well a patient is recovering after TBI.

Studies using DNA and RNA biomarkers have shown us that variations in certain genes, like one called PPP3CC, might predict how well a patient will recover from TBI [4]. This is promising, because DNA is easily accessible through the blood or saliva. 
Currently, scientists are researching new ways to use exosomes to detect certain proteins or biomarkers in the blood. In one study, mice were exposed to mild or moderate TBI. When the researchers obtained exosomes from the brains of the mice, they observed that these exosomes had lower levels of certain RNA sequences and higher levels of other RNA sequences. Through these experiments, we can see the promise of using exosomes as a means of TBI diagnosis.

\section{CONCLUSION}

The recent attention that biomarkers have been receiving these past couple of years may lead to the identification of the first effective treatment for TBI! As we learn more about the brain and how it recovers from injuries, our hope is that we will be able to find better and faster ways to diagnose brain injuries and ultimately discover new methods to treat them. In the meantime, keep your brains safe and protected!

\section{REFERENCES}

1. Lee, B., and Newberg, A. 2005. Neuroimaging in traumatic brain imaging NeuroRx 2:372-83. doi: 10.1602/neurorx.2.2.372

2. Willheim, M. 2012. Biomarkers. Wien. Med. Wochenschr. 162:453. doi: 10.1007/ s10354-012-0161-5

3. Yokobori, S., Hosein, K., Burks, S., Sharma, I., Gajavelli, S., and Bullock, R. 2013. Biomarkers for the clinical differential diagnosis in traumatic brain injury-a systematic review. CNS Neurosci. Ther. 19:556-65. doi: 10.1111/cns.12127

4. Osier, N., Bales, J., Pugh, B., Shin, S., Wyrobek, J., Puccio, A., et al. 2017. Variation in PPP3CC genotype is associated with long-term recovery after severe brain injury. J. Neurotrauma 34:86-96. doi: 10.1089/neu.2015.4343

5. Osier, N., Motamedi, V., Edwards, K., Puccio, A., Diaz-Arrastia, R., Kenney, K., et al. 2018. Exosomes in acquired neurological disorders: new insights into pathophysiology and treatment. Mol. Neurobiol. 55:9280-93. doi: 10.1007/ s12035-018-1054-4

6. Nylén, K., Öst, M., Csajbok, L. Z., Nilsson, I., Blennow, K., Nellgård, B., et al. 2005. Increased serum-GFAP in patients with severe traumatic brain injury is related to outcome. J. Neurol. Sci. 240:85-91. doi: 10.1016/j.jns.2005.09.007

7. Battista, A., Rhind, S., Hutchinson, M., Hassan, S., Shiu, M., Inaba, K., et al. 2016. Inflammatory cytokine and chemokine profiles are associated with patient outcome and the hyperadrenergic state following acute brain injury. J. Neuroinflammation 13:40. doi: 10.1186/s12974-016-0500-3

8. Kumar, R. G., Diamond, M. L., Boles, J. A., Tisherman, S. A., Kochanek, P. M., and Wagner, A. K. 2015. Acute CSF interleukin- 6 trajectories after TBI: associations with neuroinflammation, polytrauma, and outcome. Brain Behav. Immun. 45:253-62. doi: 10.1016/j.bbi.2014.12.021 
SUBMITTED: 27 September 2018; ACCEPTED: 05 February 2019;

PUBLISHED ONLINE: 26 February 2019.

EDITED BY: Amy J. Markowitz, University of California, San Francisco, United States

CITATION: Kim S, Klein P, Nguyen M and Osier N (2019) Studying Brain Injury Through the Blood: The Promise of Biomarkers. Front. Young Minds 7:27. doi: 10.3389/frym.2019.00027

CONFLICT OF INTEREST STATEMENT: The authors declare that the research was conducted in the absence of any commercial or financial relationships that could be construed as a potential conflict of interest.

COPYRIGHT @ 2019 Kim, Klein, Nguyen and Osier. This is an open-access article distributed under the terms of the Creative Commons Attribution License (CC BY). The use, distribution or reproduction in other forums is permitted, provided the original author(s) and the copyright owner(s) are credited and that the original publication in this journal is cited, in accordance with accepted academic practice. No use, distribution or reproduction is permitted which does not comply with these terms.

\section{YOUNG REVIEWER}

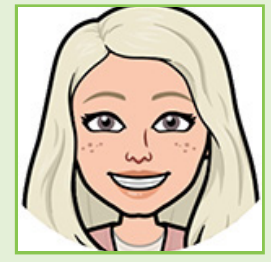

\section{BRITT, AGE: 14}

Hey! I am Britt. At the moment, I go to Beacon Academy, a Montessori and IB high school. At school, I love Math, Science, and Spanish class. I also love doing dance, cheer, choir, and playing ukulele!

\section{AUTHORS}
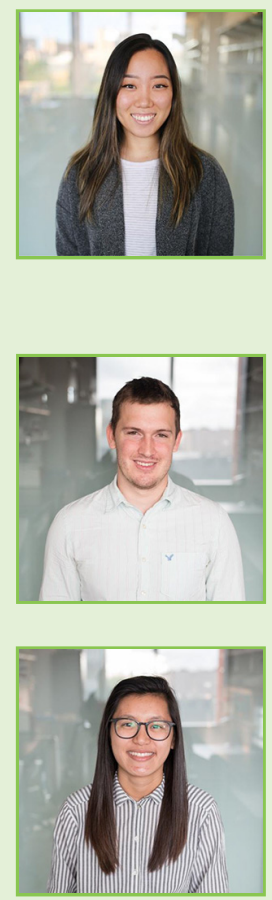

\section{STEPHANY KIM}

I am a graduate of the University of California Los Angeles (UCLA) with a Bachelor of Science in Physiological Science and a Bachelor of Arts in Russian Language and Literature. Currently, I am pursuing a career in medicine, with hopes of specializing in either neurosurgery or cardiothoracic surgery. In my free time, I enjoy backpacking, snowboarding, reading, and, of course, searching for potential biomarkers.

\section{PRESTON KLEIN}

I am currently an undergraduate student at The University of Texas at Austin, pursuing a Bachelor of Science in Human Biology. After completion of this degree, I plan on attending medical school. In my free time, I enjoy running, reading, and exploring my local community.

\section{MINDY NGUYEN}

I am currently an undergraduate student at The University of Texas at Austin, pursuing a Bachelor of Science and Arts degree in Neuroscience with a minor in Forensic Science. I plan to attend graduate school to become a Physician's Assistant and specialize in Neurosurgery. When I am not in the lab or studying, I am out taking photos and adventuring in Austin, or playing tennis. 


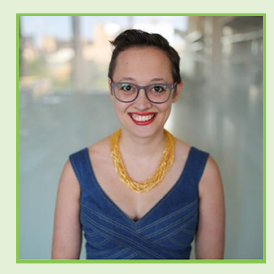

\section{NICOLE OSIER}

I am a Principal Investigator at The University of Texas at Austin. I have a Bachelor's Degree in Nutritional Science and Nursing from Michigan State University and a Ph.D. from the University of Pittsburgh. My goal is to understand what makes some individuals recover better than others after head injury and apply this information to help doctors and nurses treat it. To learn more about my laboratory, visit my website: https://nicoleosier.wixsite.com/osierlaboratory/. In my free time I enjoy spending time with my spouse and cats and traveling the world. *nicoleosier@utexas.edu 